Vietnam Journal of Mechanics, NCST of Vietnam Vol. 21, 1999, No 4 (251 - 256)

\title{
BUCKLING OF NONLINEAR CREEP PLATES
}

\author{
TO VAN TAN, PHAM QUOC DOANH \\ Hanoi University of Civil Engineering
}

\section{Introduction}

Note that [1] the buckling of structures with immediate mechanical behaviour of the material (elastic, plastic) corresponding to the bifurcation points (of a state of strain or a process of strain). However, the buckling of creep structures takes place after a determined period of time and corresponding to the pseudo-bifurcation points. In this paper the theory of pseudo-bifurcation points and a criterion of creep stability [1] are used to solve the problem on buckling of nonlinear creep plates according to Rabotnov's theory of hardening creep [2].

\section{Stability of nonlinear creep plate}

Using Rabotnov's theory of hardening creep, we have

$$
\begin{gathered}
P^{\alpha} \dot{P}_{i j}-\frac{3}{2} A \sigma^{n-1} S_{i j}=0, \\
e_{i j}=P_{i j}+\frac{3}{2} \frac{S_{i j}}{E}
\end{gathered}
$$

where

$$
\sigma^{2}=\frac{3}{2} S_{i j} S_{i j}, \quad \dot{P}^{2}=\frac{2}{3} \dot{P}_{i j} \dot{P}_{i j}
$$

$\sigma, P$ - stress intensity and creep strain intensity;

$P_{i j}$ - creep strain components;

$S_{i j}$ - components of stress deviator;

$E, A, \alpha, n$ - material constants determined by experiment.

Assume that $\sigma_{i j}^{0} \cdot e_{i j}^{0}, W^{0}$ - stress, strain, deflection in the basic state.

$\sigma_{i j}, e_{i j}, W$ - stress, strain, deflection in the adjacent state such that the "stimulus" 


$$
\begin{aligned}
\Delta \sigma_{i j} & =\sigma_{i j}-\sigma_{i j}^{0} \ll \sigma_{i j}^{0}, \\
\Delta e_{i j} & =e_{i j}-e_{i j}^{0} \ll e_{i j}^{0}, \\
\Delta W & =W-W^{0} \ll W^{0} .
\end{aligned}
$$

We shall use the basic equations in terms of "stimulus" to solve the problem on creep stability of rectangular plate $(a>b)$ with simply supported edges and compressed in the direction of long edges.

- Geometric equations

$$
\Delta e_{k s}=-z \Delta W_{k s}
$$

- Relations moment - stress

$$
\Delta M_{i j}=\int_{-h / 2}^{h / 2} \Delta \sigma_{i j} z d z, \quad h \text {-thickness. }
$$

\section{- Physical equations}

Using the theory of pseudo-bifurcation points of $N$-degree, from $(2.1)$ the "elastic analogy" can be written in following form [1], [3]

$$
\Delta \sigma_{i j}=\widetilde{E}_{i j k s} \Delta e_{k s}
$$

where

$$
\begin{aligned}
\tilde{E}_{i j k s} & =\frac{E \alpha \sigma}{E P+N \alpha \sigma}\left[\frac{2}{3} N\left(\delta_{i k} \delta_{j s}+\delta_{i j} \delta_{k s}\right)-K \frac{\sigma_{i j} \sigma_{k s}}{\sigma^{2}}\right] \\
K & =\frac{E P[N(n-1)-1]}{E P n+\alpha \sigma(N+1)}, \quad i, j, k, s=1,2
\end{aligned}
$$

- The equilibrium equations

$$
\begin{aligned}
& \Delta N_{i j, j}=0 \\
& \Delta M_{i j, i j}+N_{i j}^{0} \Delta W_{, i j}=0
\end{aligned}
$$

From the equations $(2.2),(2.3),(2.4)$, we obtain

$$
\Delta M_{i j}=-\widetilde{E}_{i j k s} \Delta W_{, k s} \frac{h^{3}}{12}
$$

From (2.6). we have

$$
\Delta M_{i j, i j}-h \sigma_{i j} \Delta W_{, i j}=0
$$


Using the criterion of creep stability $(N=2)[1]$, and substituting (2.7) into (2.8) we obtain

$$
2 \Delta W_{, i j i j}-\frac{3}{4} K \frac{\sigma_{i j} \sigma_{k s}}{\sigma^{2}} \Delta W_{, i j k s}+9 \frac{E P+2 \alpha \sigma}{E \alpha \sigma h^{2}} \sigma_{i j} \Delta W_{, i j}=0
$$

whence

$$
2\left(\frac{\partial^{4} \Delta W}{\partial x^{4}}+2 \frac{\partial^{4} \Delta W}{\partial x^{2} \partial y^{2}}+\frac{\partial^{4} \Delta W}{\partial y^{4}}\right)-\frac{3}{4} K \frac{\partial^{4} \Delta W}{\partial x^{4}}+9 \frac{E P+2 \alpha \sigma}{E \alpha \sigma h^{2}} \sigma_{11} \frac{\partial^{2} \Delta W}{\partial x^{2}}=0
$$

For simplicity, we neglect the symbol $\Delta$ in $\Delta W$, we have

$$
2\left(\frac{\partial^{4} W}{\partial x^{4}}+2 \frac{\partial^{4} W}{\partial x^{2} \partial y^{2}}+\frac{\partial^{4} W}{\partial y^{4}}\right)-\frac{3}{4} K \frac{\partial^{4} W}{\partial x^{4}}+9 \frac{E P+2 a \sigma}{E \alpha h^{2}} \frac{\partial^{2} W}{\partial x^{2}}=0
$$

For the rectangular plate simply supported we find solution of $(2.9)$ in the following form:

$$
W=C \sin \frac{m \pi x}{a} \sin \frac{\pi y}{b}
$$

Substituting (2.10) into (2.9), we have

$$
\frac{m^{2}}{2 a^{2} b^{2}}\left(\frac{m^{2} b^{2}}{a^{2}}+2+\frac{a^{2}}{m^{2} b^{2}}\right)-\frac{3}{16} K \frac{m^{4}}{a^{4}}-\frac{E P+2 a \sigma}{\alpha \sigma_{E}} \frac{m^{2}}{a^{2} b^{2}}=0
$$

Denoting

$$
\begin{gathered}
\lambda=m^{2} \frac{b^{2}}{a^{2}} ; \quad L=\frac{1}{4}\left(\lambda+2+\frac{1}{\lambda}\right), \quad \omega=\frac{\sigma}{\sigma_{E}}, \\
\sigma_{E}=\frac{4}{9} \frac{\pi^{2} E h^{2}}{b^{2}}, \quad J=\frac{E P n}{\alpha \sigma_{E}}, \quad(\mu=0.5)
\end{gathered}
$$

then from (2.11) we get

$$
2 L-\frac{3}{16} \lambda \frac{E P[2(n-1)-1]}{E P n+3 \alpha \sigma}-\left(\frac{J}{n}+2 \omega\right)=0,
$$

whence

$$
2(L-\omega)-\frac{J}{n}-\frac{3}{16} \frac{\lambda}{n} \frac{J(2 n-3)}{J+3 \omega}=0 .
$$

Performing transformations, we get

$$
J^{2}+J\left[-2 n(L-\omega)+3 \omega-\frac{3}{16} \lambda(3-2 n)\right]-6 n(L-\omega) \omega=0 .
$$

The positive solution of this equation is written as follows

$$
J=\frac{\theta}{2}+\frac{1}{2} \sqrt{\theta^{2}+24 n \omega(L-\omega)},
$$


where

$$
\theta=\frac{3}{16} \lambda-\omega+2\left[n(L-\omega)-\omega-\frac{3}{16} \lambda(n-1)\right] .
$$

The particular points of a process of strain corresponding to the minimum value of $J$, i.e. the derivative $\partial J / \partial \lambda$ must be zero, we get

$$
\frac{\partial L}{\partial \lambda}=\frac{3(2 n-3) J}{32 n(J+3 \omega)}
$$

In other side, from (2.12) we obtain

$$
\frac{\partial L}{\partial \lambda}=\frac{1}{4}\left(1-\frac{1}{\lambda^{2}}\right)
$$

Then, from (2.16), (2.17) we have

$$
\frac{3(2 n-3) J}{8 n(J+3 \omega)}=1-\frac{1}{\lambda^{2}}
$$

If $\omega=1$, the buckling occurs immediatelly and $J=0$. From (2.18) we have $\lambda=1$. If $\omega=0$ from (2.18) we get

$$
\lambda_{0}=\frac{1}{\sqrt{1+\frac{9}{2 n}}}
$$

We find that the relation $J \sim \omega$ in (2.15) is an approximate straight line on the plane $J \sim \omega$ connecting the point $(j=0, \omega=1)$ to the point $\left(J_{0}, \omega=0\right)$, (in the case $\omega=0$ we have the value $J_{0}$ ).

On the basis of (2.13) and (2.18) we have

$$
2 L+\frac{3}{16} \lambda \frac{2 n-3}{n}-\frac{J_{0}}{n}=0,
$$

then from (2.20) and (2.19) we get $J_{0}=n Q$, where

$$
Q=1+\frac{1}{2} \sqrt{1+\frac{9}{2 n}}
$$

Denoting $\eta=\frac{J}{n}=\frac{E P}{c_{\ell} \sigma_{E}}$, the approximate straight line in plane $\eta \sim \omega$ is written in the following form (the critical equation):

$$
\eta+Q \omega=Q
$$


From this it follows that

$$
\frac{E P}{\alpha \sigma_{E}}=Q-Q \omega,
$$

where

$$
P=\frac{Q(1-\omega) \alpha \sigma_{E}}{E}
$$

From the relation of hardening creep (2.1) it follows that [3]:

$$
\dot{P} P^{\alpha}=A \sigma^{n} \text {. }
$$

In this case $\sigma=$ const. We have

$$
P^{\alpha} d P=A \sigma^{n} d t \rightarrow t=\frac{P^{n+1}}{(\alpha+1) A \sigma^{n}} .
$$

Substituting (2.23) into (2.25) we obtain the formula for the critical time

$$
t_{c r}=\frac{\left[\alpha Q\left(\sigma_{E}-\sigma\right)\right]^{\alpha+1}}{A(\alpha+1) E^{\alpha+1} \sigma^{n}}
$$

where

$$
\sigma_{E}=\frac{4}{9} \frac{\pi^{2} h^{2} E}{b^{2}}, \quad Q=1+\frac{1}{2} \sqrt{1+\frac{9}{2 n}}
$$

\section{Example}

Determine the critical time for a plate made of Aluminum D16T at a temperature $250^{\circ} \mathrm{C}$ with following mechanical characteristics [4]

\begin{tabular}{|c|c|c|c|c|c|c|c|c|c|c|c|}
\hline $\begin{array}{c}\sigma \\
\left(N / m m^{2}\right)\end{array}$ & 0 & 5 & 8 & 10 & 12 & 15 & 18 & 20 & 22 & 25 & 25.8 \\
\hline$\omega=\frac{\sigma}{\sigma_{E}}$ & 0 & 0.19 & 0.31 & 0.39 & 0.47 & 0.58 & 0.7 & 0.78 & 0.85 & 0.97 & 1 \\
\hline$t_{c r}, h$ & $\infty$ & 26.53 & 11.31 & 7.11 & 4.61 & 2.44 & 1.22 & 0.71 & 0.35 & 0.035 & 0 \\
\hline
\end{tabular}

$$
E=5.9 \cdot 10^{4} \mathrm{~N} / \mathrm{mm}^{2}, \quad A=9 \cdot 10^{7}, \quad n=1.36, \quad \alpha=0.36, \quad \frac{h}{b}=0.01 .
$$

First we determine the critical stress defined by Euler's formular for the plate

$$
\sigma_{E}=\frac{4}{9} \frac{E \pi^{2} h^{2}}{b^{2}}=25.8 \mathrm{~N} / \mathrm{mm}^{2}
$$

with the help of (2.26) we find the critical time.

They are given in the table 
Construction of Diagram $\omega \sim t_{c r}$

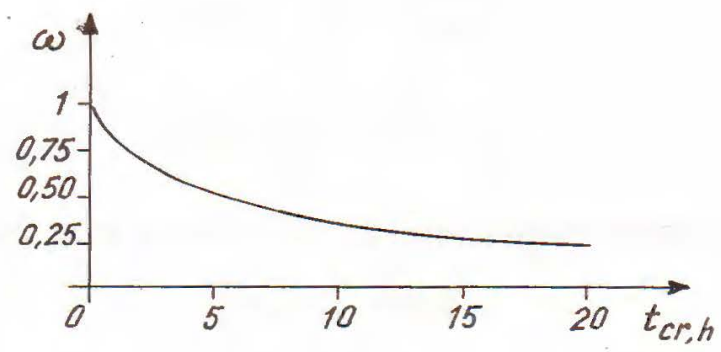

\section{Conclusion}

Using Rabotnov's non-linear creep theory (the theory most supported by experiment for metal) and Cliusnhicov's method to study creep stability the authors of the paper have considered the problem on creep buckling of plate and established the analytical formula for critical time (when the buckling of plate takes place if the load is given). From this formula it is seen that the buckling of the hardening creep plate occurs by any load, i.e. not exist the long stability limit. This is corresponding to the nonlimiting creep property of metal.

\section{REFERENCES}

1. Cliusnhicov V. D., To Van Tan. Creep stability: variant of theory and experiment, Transactions of AN, MTT, No 2, 1986.

2. Rabotnov Iu. N. Creep of structure elements, M., 1966.

3. Cliusnhicov V. D. The yielding stability of the complicated medium, Nonlinear models and problem of mechanics of deformable rigid bodies, M., 1984.

4. Cusnhesov A. N. Stability of compressed bars made of Duraluminium in creep conditions, PMTF, No 6, 1961.

Received June 17, 1999

SỰ MẤT ỔN ĐỊNH CỦA TẤM TƯ VẬT LIỆU TỪ BIẾN PHI TUYẾN

Để giải bài toán ổn định của tấm có tính chất từ biến phi tuyến được mô tả theo thuyết từ biến tái bền của Iu. N. Rabotnov, các tác giả bài báo sư dụng phương pháp xây dụng "các tương tự đàn hò̀" và tiêu chuân ổn định từ biến của V. D. Cliusnhicov. Kết quá là tìm được biểu thức thời gian tới hạn cho phép xác định thời điểm tấm raất ổn định với tải trọng xác định cho trước. Ớ đây cho thấy do tính chất từ biến không hạn chế của kim loại, tấm có thể mất ổn định cho dù tải trọng nhỏ bao nhiêu. 